\title{
Analysis of student performance through the use of two different active strategies
}

\author{
Leyla Angélica Sandoval Hamón ${ }^{1, *}$, Fernando Casani ${ }^{1}$, Jesus Rodriguez-Promeda ${ }^{1}$, and \\ Ricardo Olmos Albacete ${ }^{2}$ \\ ${ }^{1}$ Autonomous University of Madrid, Faculty of Economics and Business Studies, 28049 Madrid, \\ Spain \\ ${ }^{2}$ Autonomous University of Madrid, Faculty of Psychology, 28049 Madrid, Spain
}

\begin{abstract}
In the European Higher Education Area (EHEA), official degree studies should promote the competences and knowledge of students. This work is based on active strategies (conceptual maps and discussion panels) where students analyse and summarize the topics proposed in class, to improve their knowledge and skills. Therefore, the objective of this paper is to analyse the performance of business students by using the mentioned strategies in two different groups during the academic year 2018-2019. The implementation of this research was carried out using a quantitative approach, with mixed models (SPSS v20 software) of three dependent variables (two of knowledge and one for competences). The conclusions indicate that the group that used the panel discussion methodology increases more the acquired competences and the understanding of the basic concepts that are taught on the subject, than the group of the conceptual maps strategy.
\end{abstract}

\section{Introduction}

In the European Higher Education Area (EHEA), the regulations that standardize official degree studies consider that specific competencies related to the different areas of knowledge must be develop, as well as the basic and transversal competences that allow the integral education of students.

Taking this premise as a reference, in recent years there have been incessant changes in Higher Education that encompass the same study programs, innovative methodologies/ strategies, novel forms in evaluations, new information and communication technologies, etc. The use of alternative methodologies to lectures has proliferated in most study programs as a means of guiding students to explore new ways of building their knowledge to encourage them to acquire other skills.

A definition that has been taken as a reference of active methodologies "active learning implies different implications for students to speak and listen to in a meaningful way, writing, reading, and reflecting on the contents, ideas, problems and needs of an academic subject" $[1]$.

\footnotetext{
* Corresponding author: angelica.sandoval@uam.es
} 
Thus, some active learning strategies according to Zayapragassarazan and Kumar [2] are conceptual maps, collaborative writing, discussion panel, etc. In addition, these strategies can captivate the continuous interest of the students, reducing the problem of the lack of motivation, which can be given in the classroom by only using a traditional methodology or strategy. Specifically, active methodologies and strategies provide a prominent role for students in their learning process.

The challenge of using alternative methodologies in higher education has generated some unknowns about its effectiveness. This has led to a reflection on the new methodological strategies and the evaluation of the students.

This work is based on active strategies (conceptual maps and discussion panels), the first has to do with conceptual maps (where the relationships between the ideas and the topics suggested in the course are illustrated), while the second has to do with the discussion panels (where, for round tables or debates in class, students prepare an oral presentation); where students analyze and summarize the topics proposed in class, in order to improve their knowledge and skills.

Therefore, the objective of this work is to analyze empirically (it means, search for evidence with the data) the academic performance and the development of competences of the students of Business Sciences when using the active strategy.

\section{Method}

\subsection{Contextualization}

Degree: Business Administration

A Course: First grade. First semester academic year.

Academic years: 2018-2019

Subject: Fundamentals of Business Administration (FADE)

$\mathrm{N}^{\circ}$ Credits: 6 (150 hours)

Class: 112 Total students: 50 (Strategy: discussion panels)

Class: 115 Total students: 50 (Strategy: conceptual maps)

Course objective: It expects that the student knows the basic concepts related to the economy of the company and the role that business organizations play in their environment.

\subsection{Design and development}

\subsubsection{Phase I}

Application of an initial questionnaire (Pre-test) and a final one (Post-test) of competences and knowledge in the subject. The questionnaire of competences was adapted taking as reference the "Questionnaire of perception of educational competences of Physical Education" [3]. The adaptation of the questionnaire was validated through a pilot test with 5 students of the degree of Business Administration of the UAM..

\subsubsection{Phase II}

Design and execution of strategies (concept maps and discussion panels). The topics of the subject in which these strategies were used were "Entrepreneur, the structure of ownership and control; the market and the environment." The students had to analyze the information 
and perform the relevant work: in the case of the conceptual map, schemes through software such as "CmapTools" and oral presentations in the case of discussion panels.

The process of preparing and presenting these conceptual maps and the presentation of the discussion panels had as a reference a rubric.

\subsection{Data collection}

The data obtained by applying a questionnaire and carrying out knowledge tests to each of the two classes: class 112 (panel discussion strategy) and class 115 (concept map strategy).

To analyze the two strategies, a design was proposed in time (with a pre and a post measure) in which two dependent variables were measured on the one hand. The knowledge or performance through two measures, one that were weighted by the time through the Kahoot application (we call it Total Score) and another more conventional in which the knowledge was evaluated through the number of correct answers to a questionnaire/exam with ten questions.

On the other hand, the second dependent variable was the motivation of the students, measured from an ad hoc questionnaire constructed so that the students subjectively evaluated the competences. Once the results obtained, the two classes were compare (since each one uses different strategies).

Regarding the data related to the competences, they were analyzed from the totals obtained with the ad hoc questionnaire constructed for that purpose, whose items are measured on a Likert scale from Nothing $(=0)$, Little $(=1)$, Enough $(=2)$ and Much $(=3)$.

The students of each class received a questionnaire, before and after the completion of the semester. The internal consistency coefficient (which can be understand as a measure of reliability) was 0.738 , an acceptable value above the standard of 0.70 .

\subsection{Data analysis}

The Mixed models were conducted with our three dependent variables previously mentioned using IBM SPSS software (v20).

The first dependent variable was the total score measured from Kahoot app (defined as the time elapsed to give a correct answer). The second one was measured from an exam (number of correct answers). These dependent variables measured student knowledge. The third one was a motivational measure of the used methodology in class.

A within-subject factor called moment, with pre and post levels and a between-subject factor (the group with two classes for each distinct methodology applied) were the independent variables. The maximum likelihood was used as an estimation method.

Two random factors were estimated (variance for subjects or level-2 variance and residuals or level-1 variance). Four fixed effects were estimated: the intersection, main effect for group, the main effect for moment and interaction effect.

The interest was focused in the interaction effect to study if one methodology was more efficient than the other one, to see if one group change differently respects the other group between pre and post moments in each defined dependent variable.

\section{Results}

\subsection{Knowledge}

The results of the mixed models for the scores on the Kahoot total score test and from the exam are present. Total score (Kahoot) descriptive are shown in Table 1. 
Table 1. Total scores (Kahoot) for the two classes in the pre and post moments.

\begin{tabular}{|c|c|c|c|c|c|}
\hline \multirow{2}{*}{\multicolumn{2}{|c|}{ Statistics }} & \multicolumn{2}{|c|}{ Class 112} & \multicolumn{2}{|c|}{ Class 115} \\
\hline & & Pre-test & Post-test & Pre-test & Post-test \\
\hline \multicolumn{2}{|c|}{$\mathrm{N}$} & 35 & 31 & 42 & 37 \\
\hline \multicolumn{2}{|c|}{ Mean } & 5077.26 & 7338.16 & 4354.71 & 5692.57 \\
\hline \multicolumn{2}{|c|}{ Median } & 5212.00 & 7095.00 & 4556.00 & 5912.00 \\
\hline \multicolumn{2}{|c|}{ Standard deviation } & 1697.01 & 2192.66 & 1376.40 & 1629.11 \\
\hline \multicolumn{2}{|c|}{ Assymetry } & -0.21 & 0.15 & -0.45 & -0.66 \\
\hline \multicolumn{2}{|c|}{$\begin{array}{l}\text { Standard error for } \\
\text { asymetry }\end{array}$} & 0.40 & 0.42 & 0.37 & 0.39 \\
\hline \multicolumn{2}{|c|}{ Kurtosis } & 0.48 & -1.19 & 0.54 & 0.29 \\
\hline \multicolumn{2}{|c|}{ Standard error for Kurtosis } & 0.78 & 0.82 & 0.72 & 0.76 \\
\hline \multirow{3}{*}{ Percentiles } & 25 & 4115 & 5380 & 3468 & 4964 \\
\hline & 50 & 5212 & 7095 & 4556 & 5912 \\
\hline & 75 & 6225 & 8781 & 5157 & 6732 \\
\hline
\end{tabular}

On the one side, it was found a significant main effect in the moment factor as it was expected $(\mathrm{F}(1,78)=33.06, \mathrm{p}<.001)$. Thus, the performance in the Kahoot scores increased significantly on average. A marginally main effect was found for the between factor (group): $(\mathrm{F}(1,140)=3.33, \mathrm{p}=.070)$. In particular, the group of 112 outperformed the group of 115 .

Finally, a marginal interaction effect was found for the moment and group factors. Group 112 increase their performance by more than 115 group between pre and post moments, and it can be conclude that the methodology used in this group was more effective.

The other dependent variable was the number of correct answers on the exam (see Table $2)$. In this case, it was not found a significant interaction effect $(F(1,81)=0.196, p=.660)$.. In fact, the only significant effect was the main effect of the within moment factor: $\mathrm{F}$ $(1,76)=12.13, p=.001)$. As was expected, the average number of correct answers increased between post-test and pre-test. However, non-significant differences were found between the two classes $(F(1,140)=0.004, p=.953)$.

Table 2. Correct answers (knowledge exam) for the two classes in the pre and post moments.

\begin{tabular}{|c|c|c|c|c|c|}
\hline \multirow{2}{*}{\multicolumn{2}{|c|}{ Statistics }} & \multicolumn{2}{|c|}{ Class 112} & \multicolumn{2}{|c|}{ Class 115} \\
\hline & & Pre-test & Post-test & Pre-test & Post-test \\
\hline \multicolumn{2}{|c|}{$\mathrm{N}$} & 35 & 31 & 42 & 37 \\
\hline \multicolumn{2}{|c|}{ Mean } & 5,74 & 7.13 & 5.76 & 6.95 \\
\hline \multicolumn{2}{|c|}{ Median } & 6,00 & 7.00 & 6.00 & 7.00 \\
\hline \multicolumn{2}{|c|}{ Standard deviation } & 1,633 & 1.455 & 1.792 & 1.929 \\
\hline \multicolumn{2}{|c|}{ Assymetry } & $-0,55$ & -0.31 & -0.42 & -0.88 \\
\hline \multicolumn{2}{|c|}{ Standard error for asymetry } & 0,40 & 0.42 & 0.37 & 0.39 \\
\hline \multicolumn{2}{|c|}{ Kurtosis } & 0,81 & -0.82 & 0.91 & 0.61 \\
\hline \multicolumn{2}{|c|}{ Standard error for Kurtosis } & 0,78 & 0.82 & 0.72 & 0.76 \\
\hline \multirow{3}{*}{ Percentiles } & 25 & 6 & 5 & 6 & 6 \\
\hline & 50 & 7 & 6 & 7 & 7 \\
\hline & 75 & 8 & 7 & 8 & 8 \\
\hline
\end{tabular}


Thus, we found that both groups, 112 y 115, increased the performance between pre and post moments, but there were no evidences of the superiority of one methodology respect to the other one.

\subsection{Competences}

The table 3. shows the distribution of the answers of the students before and after the semester, there is a majority of responses both in the pre-test moment and in the post-test moment that are concentrated in the enough category.

Table 3. Distribution of scores (\%) to the competency questionnaire in the two moments of the

\begin{tabular}{|c|c|c|c|c|c|}
\hline & & None & Low & Moderate & High \\
\hline \multirow{10}{*}{ Pre-test } & Analyze and synthesize & $1,1 \%$ & $43,2 \%$ & $48,9 \%$ & $6,8 \%$ \\
\hline & Organize and plan & $0,0 \%$ & $20,5 \%$ & $58,0 \%$ & $21,6 \%$ \\
\hline & To communicate in an orally and writing way & $3,4 \%$ & $37,5 \%$ & $54,5 \%$ & $4,5 \%$ \\
\hline & To communicate gesturally and corporeally & $9,1 \%$ & $39,8 \%$ & $44,3 \%$ & $6,8 \%$ \\
\hline & Teamwork & $1,1 \%$ & $14,8 \%$ & $69,3 \%$ & $14,8 \%$ \\
\hline & Critical and reflective reasoning & $4,5 \%$ & $40,9 \%$ & $48,9 \%$ & $5,7 \%$ \\
\hline & Develop autonomous learning & $1,1 \%$ & $34,1 \%$ & $52,3 \%$ & $12,5 \%$ \\
\hline & Adapt to new situations & $1,1 \%$ & $15,9 \%$ & $60,2 \%$ & $22,7 \%$ \\
\hline & Develop creativity & $6,8 \%$ & $37,5 \%$ & $43,2 \%$ & $12,5 \%$ \\
\hline & Use (ICT) in the field of study & $5,7 \%$ & $28,4 \%$ & $46,6 \%$ & $19,3 \%$ \\
\hline \multirow{10}{*}{ Post-test } & Analyze and synthesize & $0,0 \%$ & $31,2 \%$ & $66,7 \%$ & $2,1 \%$ \\
\hline & Organize and plan & $0,0 \%$ & $35,4 \%$ & $60,4 \%$ & $4,2 \%$ \\
\hline & To communicate in an orally and writing way & $2,1 \%$ & $33,3 \%$ & $60,4 \%$ & $4,2 \%$ \\
\hline & To communicate gesturally and corporeally & $12,5 \%$ & $43,8 \%$ & $39,6 \%$ & $4,2 \%$ \\
\hline & Teamwork & $0,0 \%$ & $12,5 \%$ & $66,7 \%$ & $20,8 \%$ \\
\hline & Critical and reflective reasoning & $0,0 \%$ & $52,1 \%$ & $47,9 \%$ & $0,0 \%$ \\
\hline & Develop autonomous learning & $0,0 \%$ & $29,2 \%$ & $52,1 \%$ & $18,8 \%$ \\
\hline & Adapt to new situations & $0,0 \%$ & $31,2 \%$ & $52,1 \%$ & $16,7 \%$ \\
\hline & Develop creativity & $6,2 \%$ & $41,7 \%$ & $47,9 \%$ & $4,2 \%$ \\
\hline & Use (ICT) in the field of study & $4,2 \%$ & $27,1 \%$ & $54,2 \%$ & $14,6 \%$ \\
\hline
\end{tabular}

Results from the mixed model found marginally significant differences between classes $(\mathrm{F}(1,132)=3.163, \mathrm{p}=.078)$ and a non-significant interaction effect: $\mathrm{F}(1,132)=1.885, \mathrm{p}=$. 172. Although the results did not reach significance, the group 112 had higher competence scores and, on the contrary, the group 115 showed a decrease in competence scores.

\section{Conclusions}

The analysis of the competences and the knowledge in two classes of the subject FADE, had as a point of reference the same contents and two strategies (conceptual maps and discussion panels) these were used in two different classes (Class 112- Discussion Panels and Class 115: conceptual maps).

In this framework, the experience sought to contribute to the process of building learning in other ways. 
This strategy was useful to organize the ideas, find other ways to present them and clarify doubts about content. This is corroborate by the results of the knowledge tests where the levels of academic achievement of the students in both classes increased.

Regarding the competences, the students of class 112 (strategy of discussion boards) had better results than class 115 (strategy of concept maps). One of the reasons that was detected as improvement is the need to provide more training to students in the use of software to present the concept maps.

\section{References}

1. C. Meyers, Lee, T.B. Jones, Jossey-Bass Inc., Publishers, (1993)

2. Z. Zayapragassarazan, S. Kumar, Online Submission, 19 (2012)

3. A. Palacios Picos, V. López-Pastor, A. Fraile Aranda, RIMCAFD. (to be published) 